\title{
EFFECTS OF ETHANOL AND/OR CHLOROQUINE WITH LOW PROTEIN DIETARY INTAKE ON SOME BIOCHEMICAL PARAMETERS IN MALE RATS
}

\author{
Mbajiorgu $\mathrm{EF}^{1^{*}}$, Vlok $\mathrm{W}^{2}$, Aire $\mathrm{TA}^{3}$ and M Alberts ${ }^{4}$
}

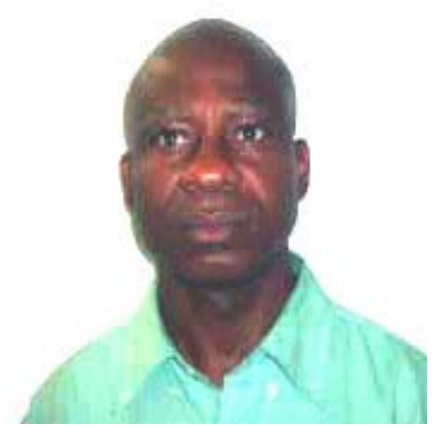

Ejikeme Mbajiorgu

*Corresponding author email: ejifun@gmail.com

${ }^{1}$ Department of Human Anatomy and Histology, School of Medicine, University of Limpopo, Private Bag, X1106, Sovenga 0727, Limpopo Province, South Africa.

${ }^{2}$ Department of Zoology, University of Limpopo

${ }^{3}$ Department of Preclinical Veterinary Studies, St. George's University, Grenada. WI.

4 Department of Chemical pathology, University of Limpopo, 


\section{ABSTRACT}

In malaria-endemic developing countries, plagued with malnutrition, patients undergoing chloroquine $(\mathrm{Q})$ treatment on prolonged basis often consume ethanol (E) regularly. This may constitute a serious health problem. The objective of this study was to investigate whether concurrent administration of $\mathrm{E}$ and $\mathrm{Q}$ under conditions of protein malnutrition may impact negatively on biochemical parameters. An experimental study was conducted to investigate biochemical effects of $\mathrm{E}$ and/or $\mathrm{Q}$ associated with protein malnutrition in adult male Sprague Dawley rats. Two groups of adult male Sprague-Dawley rats were fed either normal protein diet (NP, 15\%) or low protein diet (LP, 6\%). Each diet group includes the controls (NPC, LPC), chloroquine- (Q); [NPQ; LPQ], ethanol- (E); [NPE; LPE \} or both chloroquinine and ethanol (NPEQ; LPEQ) treated groups. Chloroquine diphosphate $\left(10 \mathrm{mg}, \mathrm{kg}^{-1}\right.$ body weight per rat) was administered intramuscularly, on days $0,10,20$, and 30 to appropriate groups, while $6 \% \mathrm{E}$ in drinking water was provided ad libitum to Etreated groups. Drinking water was given to Q-treated groups, and physiological saline was injected to E-treated groups. After 40 days, blood was collected, under ether anesthesia, by cardiac puncture for biochemical analysis. Results showed that concurrent treatment of E and Q slightly decreased TP and albumin (Alb) levels in LPEQ-rats compared to LPC, LPE and LPQ rat groups. Furthermore, TP level was substantially and significantly elevated in NPEQ-rats compared to LPEQ, NPE and NPQ rat groups. Ethanol and Chloroquine interaction exacerbated ALP and ALT activities in LPEQ-rats compared to NPEQ- rats. Urea depression was enhanced in LPEQ- than in NPEQ-rats. Creatinine levels were increased in all treatment groups. The results suggest increased toxic effect of concurrent intake of E and Q in LP- fed rats. The findings show that LP dietary intake potentiates adverse effects of combined $\mathrm{E}$ and $\mathrm{Q}$. This has implications for clinical practice, especially in poor malaria endemic countries where prevalence of protein malnutrition is often high, and patients who consume alcohol while on chloroquine, are at greater risk of severe toxic effect of combined $\mathrm{E}$ and $\mathrm{Q}$ intake.

Key words: ethanol, chloroquine, biochemical-indices, rats, malnutrition 


\section{INTRODUCTION}

Chloroquine $(\mathrm{Q})$ remains the drug of choice for treatment of malaria in malariaendemic developing countries primarily because it is cheap and readily available [1]. In western Uganda, for example, misuse/abuse of drugs such as $Q$ through self medication represents $87.2-94.6 \%$ of drug use [2]. In these poor settings, with malaria endemicity, individuals / patients on $\mathrm{Q}$, for treatment of malaria or rheumatoid arthritis, often consume alcohol (ethanol; E) regularly [3]. Hence, because of widespread poverty and malnutrition [4], intake of Q and E concurrently with protein deficient diets is not uncommon. This may constitute a serious health problem.

Studies have shown that chloroquine (Q), a 4-aminoquinoline drug, affects a wide range of biochemical processes, including the inhibition of key metabolic enzymes such as alcohol dehydrogenase, succinate dehydrogenase and glucose 6-phosphate dehydrogenase $[5,6]$. Ethanol (E) interferes with several metabolic pathways, resulting in derangements in protein, carbohydrate and lipid metabolism during its oxidation in the body [7]. It also affects renal function by decreasing glomerular filtration rate, aldosterone synthesis and alteration of kidney structure [8].

Concurrent administration of $\mathrm{Q}$ with other drugs (such as didanosine, hydroxyurea, mepacrine among others), has been shown to either potentiate or attenuate the effects of the drugs $[8,9,10]$. Effects of $\mathrm{E}$ alone, and in combination with other drugs has been reported [7, 3]. However, only one study has reported the effect of concurrent intake of $\mathrm{E}$ and $\mathrm{Q}$, on heamatological parameters [8]. This study focused on select biochemical changes associated with intake of $\mathrm{E}$ and/or $\mathrm{Q}$ with protein malnutrition.

\section{MATERIALS AND METHODS}

\section{Rats}

Adult male Sprague-Dawley rats between 3 and 4 months old were used in the study. The rats were bred and housed at the Animal House, Faculty of Medical Sciences, University of Zimbabwe. The rats were housed in cages and maintained on a 12-hour light / 12-hour dark regimen. The rat cages had pervious floors which permitted faeces and urine to pass into a lower compartment filled with sawdust preventing any contamination of the rats.

\section{Experimental Design}

The rats were randomly assigned to two major groups based on their dietary protein level: Normal protein diet (NP, 15\%) and low protein diet (LP, 6\%) groups - see Table 1 for composition and proximate analysis of the feed. Each diet group of rats was further sub-divided into four sub-groups that served as controls or received chloroquine (Q) or ethanol (E) or both chloroquine diphosphate and ethanol (EQ) for 40 days. The treatment groups (with about five-seven rats each) were thus identified as controls on normal protein (NPC) or low protein (LPC), rats given chloroquine only whilst on normal protein (NPQ) or low protein (LPQ), rats on ethanol treatment 
only whilst on normal protein (NPE) or low protein (LPE) and rats on both ethanol and chloroquine treatment whilst on normal protein NPEQ) or low protein (LPEQ).

Chloroquine (10 $\mathrm{mg} \mathrm{kg}^{-1}$ body weight per rat) was administered intramuscularly, on days $0,10,20$, and 30 to the NPQ, LPQ, NPEQ and LPEQ groups while $6 \% \mathrm{E}$ in drinking water was provided ad libitum to the NPE, LPE, NPEQ and LPEQ groups, as reported by Akingbemi and Aire [11]. Drinking water, being the vehicle for E, was given to the groups on only Q treatment (NPQ; LPQ). A volume of physiological saline, the vehicle for $\mathrm{Q}$, equivalent to $\mathrm{Q}$ injected rats, was injected to the groups receiving only $\mathrm{E}$ (NPE; LPE). After 40 days of treatment, the rats were weighed and deeply anaesthetized with ether. Blood was collected by cardiac puncture into appropriately labeled sterile tubes containing K-EDTA. The rats were then sacrificed by anaesthetic overdose.

\section{Biochemical Analyses}

The activities of serum alkaline phosphatase (ALP) and alanine aminotransferase (ALT) and the concentrations of total protein, albumin, creatinine, and urea were determined on an autoanalyser (Electro-Nucleonics Inc., Altaire $\mathrm{T}^{\mathrm{m}}$, New Jersey, U.S.A.). Serum globulin was derived as the difference between the total protein and albumin. Enzyme activity was determined at $37^{\circ} \mathrm{C}$. All reagent kits were obtained from Schiapparelli Biosystems, New Jersey.

\section{Organ weights}

The wet weight of the heart, kidneys, lungs, liver, pancreas, spleen and adrenals, obtained on a mettler analytical balance, (PE 1600, Mettler Instrument AG; Switzerland) were expressed as proportions (\%) of the body weight, for the purpose of comparison.

\section{Data presentation and statistical analysis}

The descriptive statistical analysis was done using SPSS 12.0 for windows. Values are presented as means \pm SEM. All the treated groups were compared with the controls. The nutritional effect was assessed by comparing the groups with similar treatment but placed on different diets. Student's $t$-test was used to test for differences in all the comparisons. A value of $p<0.05$ was considered significant.

\section{Ethical consideration}

Ethical clearance for this study was obtained from the Ministry of Agriculture, Zimbabwe, as stipulated in the Scientific Animal Experiment Act, 1963. The University of Limpopo ethical committee also approved the project.

\section{RESULTS}

\section{General Findings}

All animals were in good bodily condition throughout the experiment. There were no unplanned deaths recorded. Feed and fluid intake increased marginally in all the groups during the experiment, but slight decreases were recorded in NPEQ, LPE, and

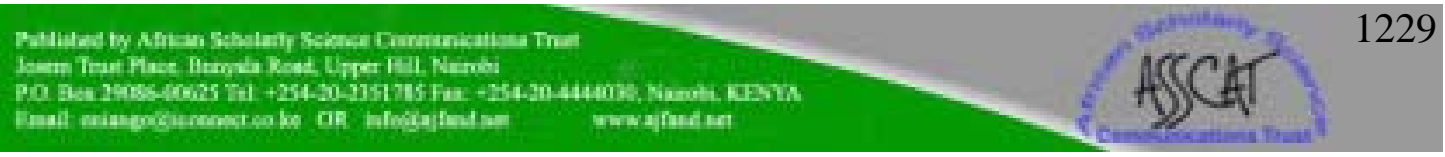


LPEQ groups in the last 7 days before sacrifice. At sacrifice, NPEQ, LPE and LPEQ rats showed some fatty infiltration of the liver.

\section{Organ weights}

The relative organ weights were as shown in Table $2 \mathrm{~A}$ and $2 \mathrm{~B}$. Protein malnutrition, ethanol and/or chloroquine administration caused decreases in body weight which were significant in all the groups compared with NPC-rats (Table 2A). The LPEQ rats had actually lost some weight. The relative sizes of the heart were significantly reduced in all groups compared with NPC-rats (Table 2A), but not among the LP-fed rats (Table 2B). The kidney sizes decreased significantly in NPE; LPC; LPQ and LPEQ rats. The relative weight of the liver was significantly reduced in NPEQ, LPE, LPQ $(P=0.05)$ and LPEQ rats and the spleen in NPE and NPEQ rats and also in LPC, LPE, LPQ and LPEQ $(p<0.05)$ rats (Table 2A). The relative weight of the pancreas was increased significantly in LPC and LPQ rats and the adrenal gland was enlarged in NPE, LPE and LPQ rats $(P<0.05$ ), (Tables $2 \mathrm{~A}$ and $2 \mathrm{~B}$ ). A greater decrease in relative organ weights (heart, lungs, pancreas and adrenals) in LPEQ rats compared to either LPE or LPQ rats (Table 2B).

\section{Serum Biochemistry}

The biochemical parameters are presented in figures 1 to 4 and Table 3. Total protein (TP) decreased significantly in NPE and NPQ, but with no significant changes in LPE, LPQ, LPEQ and NPEQ rats in comparison with the control groups (Fig. 1; Table 3). Albumin (Alb) was significantly reduced in NPE, NPQ and NPEQ rats. Globulin (Glb) was significantly increased in NPE and NPEQ groups in comparison with the control rats (Fig. 1).

The ALP and ALT activities increased significantly in all the treated groups when compared with the control groups (Fig 2). Ethanol (more than Q) significantly increased ALP and ALT activities in both dietary regimens (Table 3; Fig. 2). Both ALP and ALT activities were elevated $(p<0.05)$ in LP- than in NP- rat groups. The ALP activity in NPEQ group was slightly above the level in NPQ rats, but below the level in NPE rats $(p<0.05)$. In LPEQ group, ALP activity was increased above the levels in LPE and LPQ groups $(p<0.05)$. The activity of ALT was significantly elevated in NPEQ- and LPEQ-rats relative to NPQ, NPE and LPQ, LPE groups respectively (Fig. 2).

Urea was reduced in NPQ and NPEQ rats $(p<0.05)$ compared to control rats (Fig. 3; Table 3). In LPE and LPQ rats, urea level was increased compared to LPC rats $(p<$ $0.05)$ (Table 3). Urea level was higher in NP- than in LP-treated groups $(p<0.05)$. Urea level in NPEQ rats was reduced to a level between the levels in NPE and NPQ rats, while in LPEQ rats; urea level was lower than the levels in LPE and LPQ rats (Fig. 3). In NPQ rats, urea was reduced compared to NPE and NPEQ groups ( $p<$ 0.05 ), and also in LPE- compared to LPQ group $(p<0.05)$ (Fig. 3; Table 3).

Creatinine increased in all the groups in comparison with the control groups $(p<$ 0.05) (Fig. 4). In NPEQ rats, creatinine was reduced below the levels in NPE and

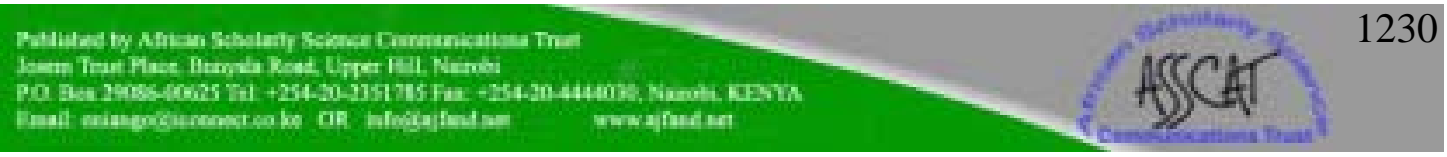


NPQ rats $(p<0.05)$ (Fig.4; Table 3). In LPEQ-rats, it was reduced below the level in LPQ rats $(p<0.05)$. Chloroquine (more than E) increased creatinine levels in both dietary groups $(p<0.05)$ (Fig. 4$)$.

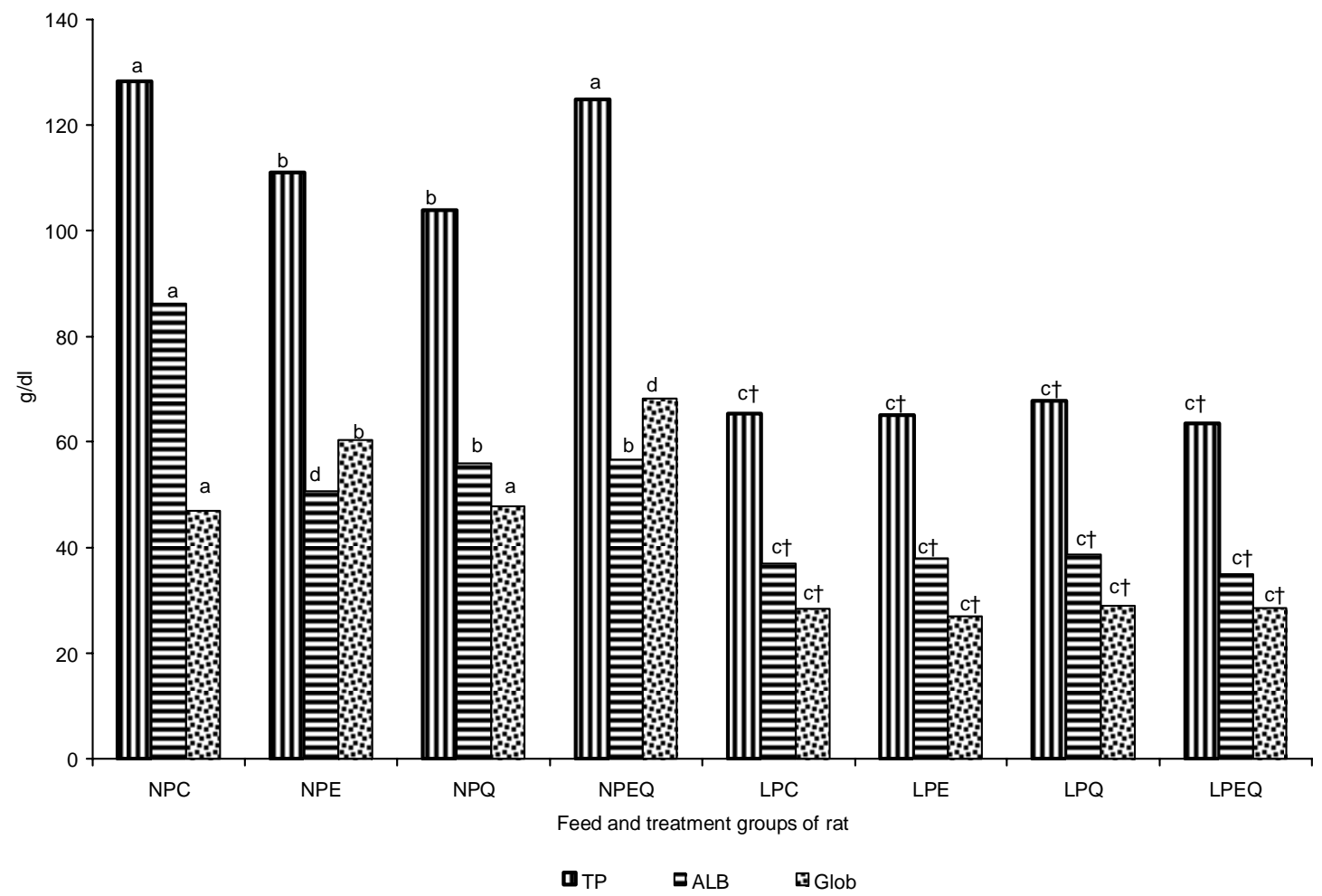

Figure 1: Serum total protein (TP), albumin (Alb) and globulin (Glb) levels in rats fed normal or low protein diet and treated with ethanol and/or chloroquine

' $a$ '= NPC and similar values for each of the parameters. Columns (values) with different alphabets are significantly different (i.e. 'a' similar to 'a' but significantly different from ' $\mathrm{b}$ ' or ' $\mathrm{c}$ ' or 'd' and e)( $p$-values are: a vs. $\mathrm{b} ; p<0.04$; $\mathrm{a}$ vs. $\mathrm{c} ; p<0.001$; a vs. $\mathrm{d} ; p<0.001$; a vs. e; $p<0.004)$

' $\dagger$ ' indicates significant dietary effect on a particular treatment (that is, comparison between the NP and LP groups such as NPC/LPC, NPE/LPE etc; $P<0.001$ mainly in all comparisons). 


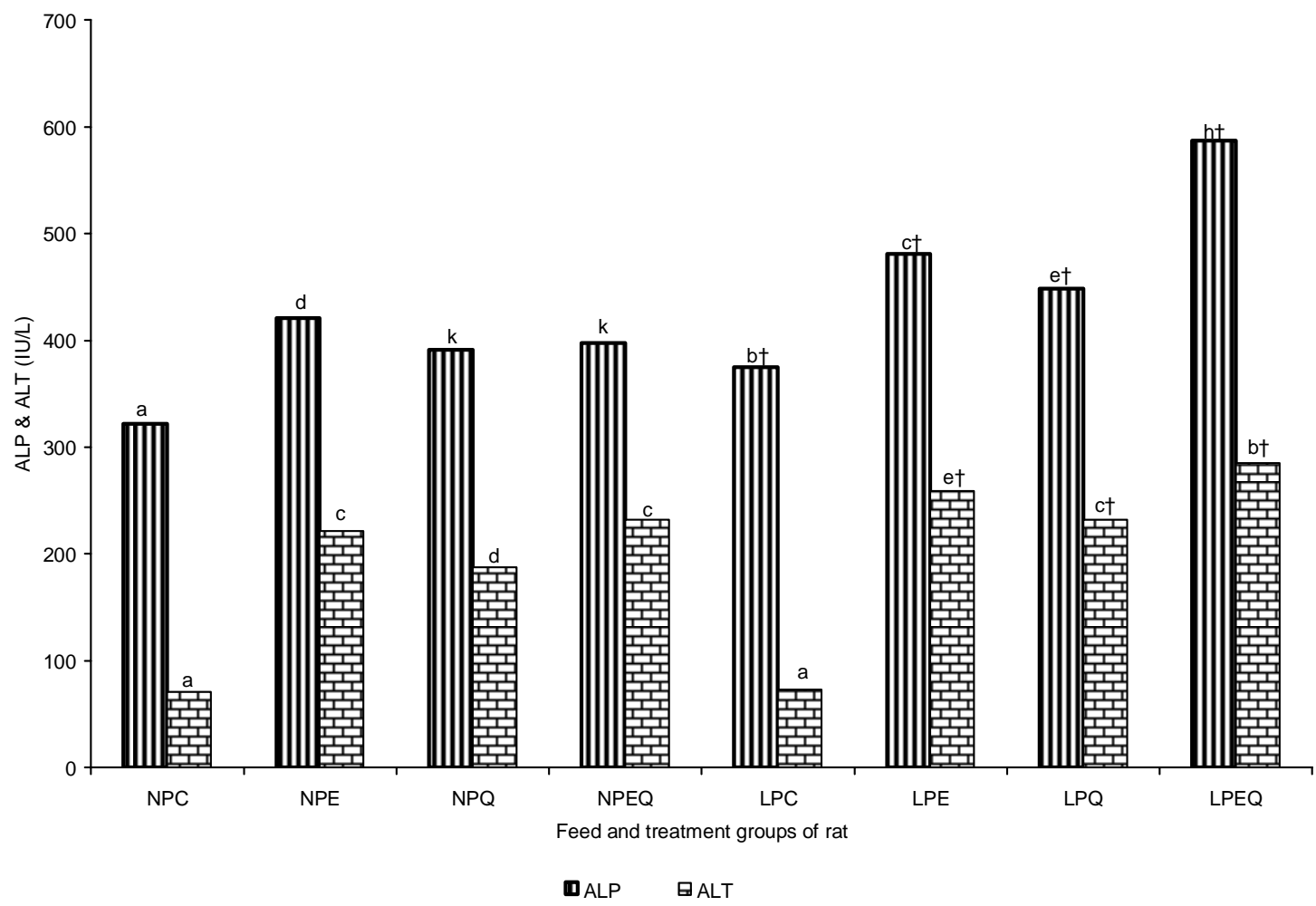

Figure 2: Serum ALP and ALT concentrations in rats administered ethanol and/or chloroquine and protein malnutrition

Columns (values) with different alphabets are significantly different, $p<0.001$ in all comparisons.

'† indicates significant dietary effect on a particular treatment (that is, comparison between the NP and LP groups such as NPC/LPC, NPE/LPE etc; $p<0.001$ in all comparisons). 

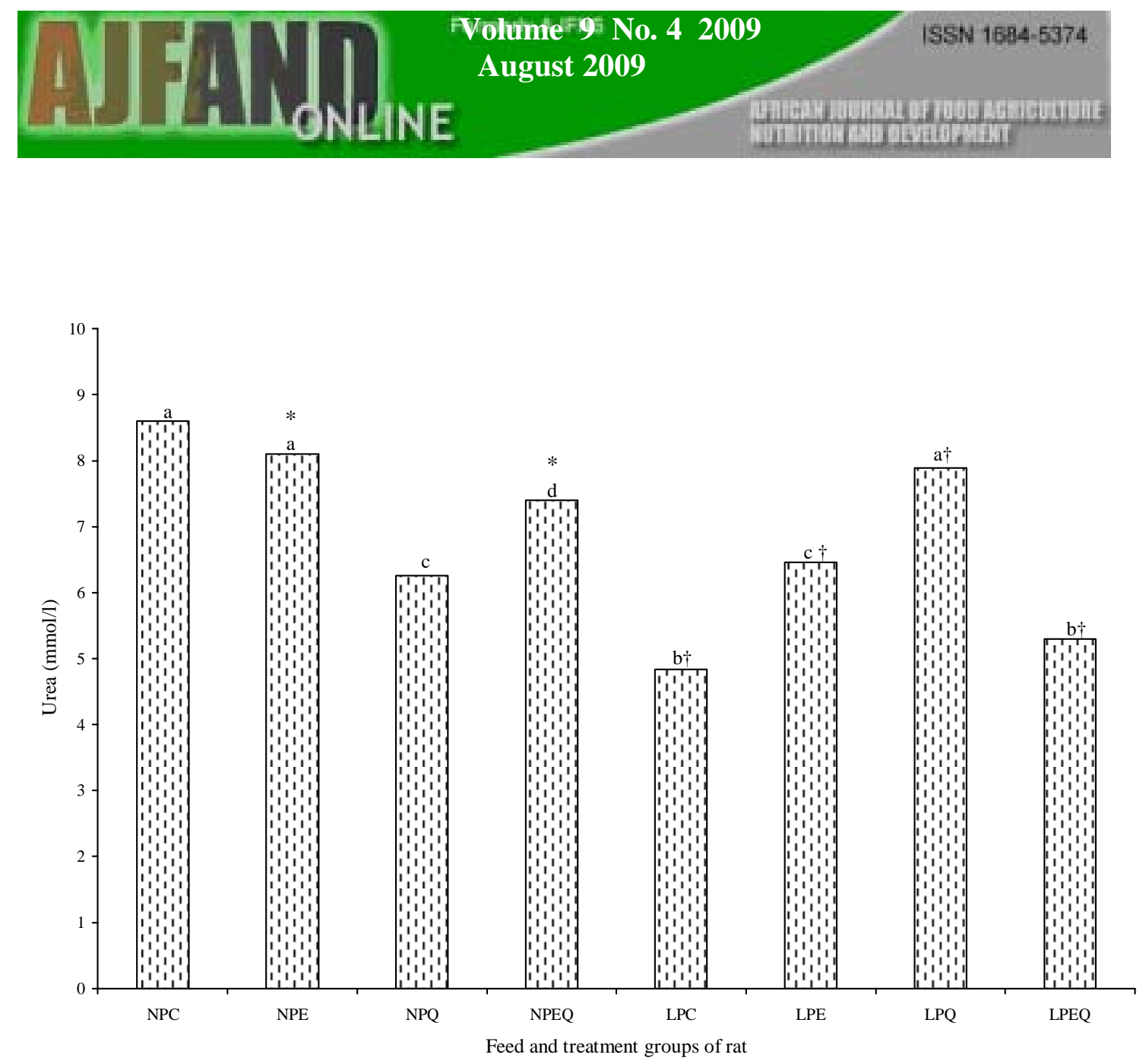

Figure 3: Serum levels of urea in ethanol and/or chloroquine-treated rats, fed normal or low protein diet

All alphabets are significantly different from each other (' $a$ ' is similar to ' $a$ ' but, significantly different from $\mathrm{b}$ or $\mathrm{c}$ or $\mathrm{d} ; p<0.001$ in all comparisons except a vs. $\mathrm{d} ; p<0.05$ )

'*' is similar to '* '

، $\dagger$ indicates significant dietary effect on a particular treatment (i.e. NPC/LPC, NPE/LPE etc; $p<0.001$ in all comparisons) 


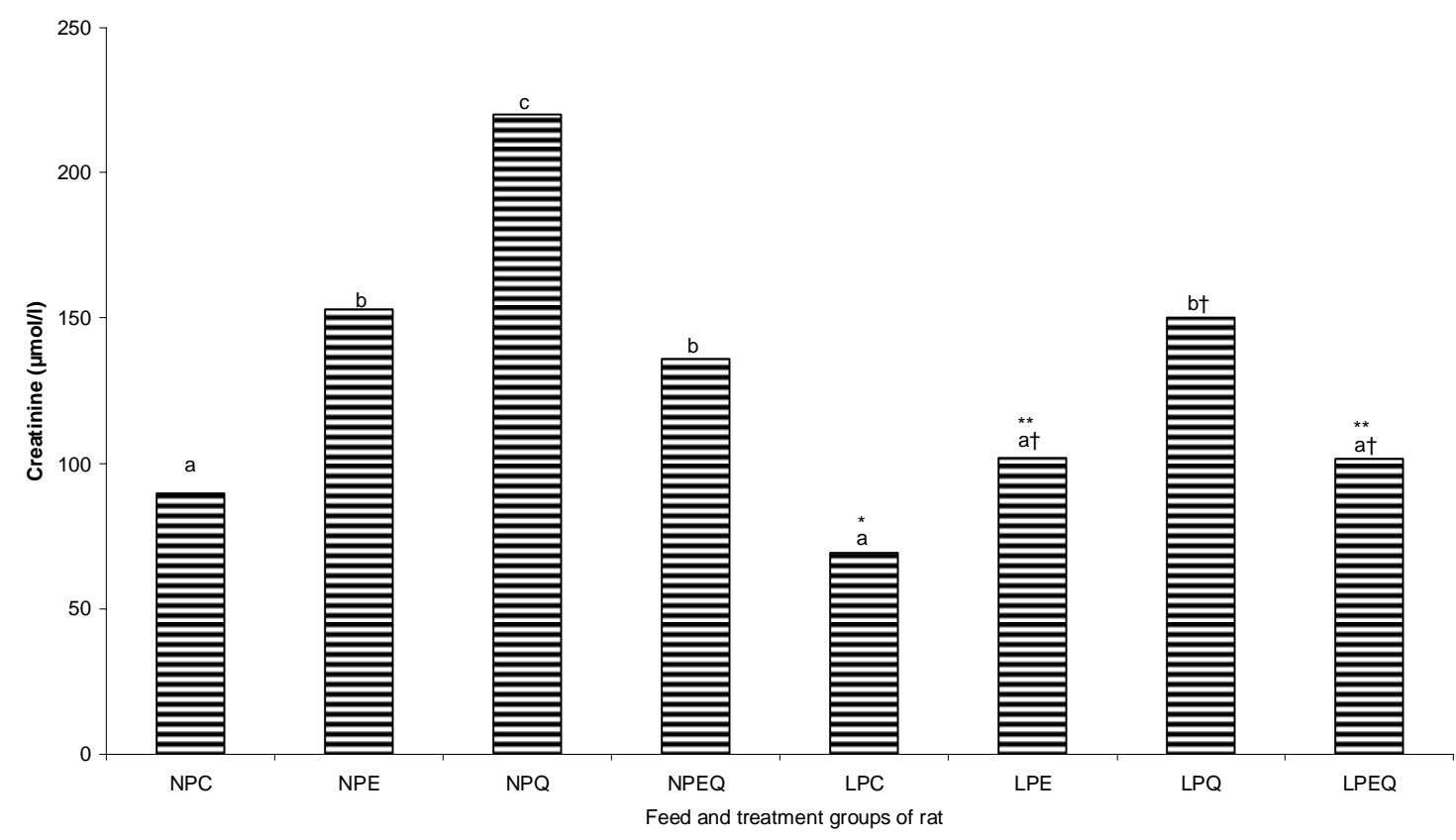

Figure 4: Serum creatinine concentrations in ethanol and/or chloroquine treated rats, fed normal or low protein diet.

' $a$ ' is similar to ' $a$ ' but, significantly different from $b, c$ and $d$; and $b$ is significantly different from $\mathrm{c} ; p<0.001$ in all comparisons.

' $*$, is significantly different from ‘ $* *$ ،

' $\dagger$ 'indicates significant dietary effect on a particular treatment (i.e. NPC/LPC, NPE/LPE etc; $p<0.004$ in all comparisons).

\section{DISCUSSION}

This study explored the effect of concurrent intake of $Q$ and $E$ under protein malnourished dietary status. Concurrent presence of $\mathrm{E}$ and $\mathrm{Q}$ in the body may either be due to misuse/abuse of these drugs, individual habits and/or disease conditions. Adopted experimental design is typical of prevalent conditions in malaria-endemic and often impoverished, developing countries.

Two levels of controls (normal and low protein controls, NPC, LPC) were employed so as to determine the combined effects of $\mathrm{E}$ and $\mathrm{Q}$ associated with protein malnutrition. Though some overlapping effects might still be obscured, loss of body weight, and decrease in relative organ weights (heart, liver, spleen and pancreas) in 
LPEQ- treated rats, show that malnutrition can enhance adverse effect of combined intake of E and Q. Levels of TP and Alb were slightly lower in LPEQ- treated rats than in LPC, LPE and LPQ - treated rats. This suggests greater adverse effect of combined $\mathrm{E}$ and $\mathrm{Q}$ in LPEQ- treated rats. On the other hand, higher TP level in NPEQ-treated rats compared to levels in NPE- and NPQ- treated rats and also to LPEQ-treated rats suggests that NP-dietary intake may ameliorate adverse effects of combined intake of $\mathrm{E}$ and $\mathrm{Q}$.

Differences in amino acid concentration of the two diets may account for the general increases in TP, Alb and Glb levels in NP-treated groups suggesting beneficial effects of NP- dietary intake in concurrent $\mathrm{E}$ and $\mathrm{Q}$ presence in the body. Normal protein intake can increase metabolism and excretion of $\mathrm{E}$ and $\mathrm{Q}$, leading to reduction in their individual toxicity and increased TP level in NPEQ- treated rats [12]. Previous studies have demonstrated that nutritional status may modulate adverse effect of combined presence of $E$ and Q [13, 14]. Inhibition of protein synthesis by E and Q may account for the decreased TP and Alb levels in NPE- and NPQ- treated rats compared to control rats. This is consistent with the findings in earlier reports $[15,16,17,18]$.

Furthermore, ALT and ALP levels were higher in LP-groups compared to NP-groups. Previous studies have shown that increase in ALT and ALP activities are indicative of hepatic dysfunction [11, 19]. Increase of ALP activities is also associated with cholestatic lesions [20]. Higher elevations of ALT and ALP activities amongst the LPgroups suggest greater hepatic damage in LP- groups. Furthermore, also suggesting that consistent intake of diets high in protein content may ameliorate the adverse effects of combined $\mathrm{E}$ and $\mathrm{Q}$ intake.

Low serum urea in LPC rats is consistent with findings of previous studies [14, 21]. Significant depression of urea level in NPQ- and slightly in NPE- rats suggests impairment of the ability of the liver to deaminate proteins by Q and E in NP-diet; serum urea is a product of protein degradation by the liver. On the other hand increased urea levels in LPE and LPQ suggests altered kidney function [8]. Renal effects of $E$ and $Q$ leading to increased urea level have previously been reported [22, 23]. Though, the present study did not include analysis of liver iron content, it has been demonstrated in a previous study that low protein diets increase liver iron content [24] which in turn may enhance E hepatotoxicity [25, 26].. This may explain the depression in urea level in LPEQ-treated rats compared to NPEQ-treated rats. Hepatotoxicity and associated renal dysfunction may account for the different urea levels in LPEQ- and NPEQ- treated rats.

Additionally, increased serum creatinine levels in $\mathrm{E}$ and/or $\mathrm{Q}$ treatments, an indication of alterated renal function, is consitent with previous findings [23]. Lower creatinine levels in NPEQ- and LPEQ- rat groups (compared to NPE-, NPQ- rat groups and LPE- , LPQ- rat groups respectively) suggest reduction in adverse effects probably due to interaction between $\mathrm{E}$ and $\mathrm{Q}$ in the liver. However, higher creatinine level in LPEQ- than in NPEQ- rat groups suggests greater toxic effect of concurrent presence of $E$ and $Q$ in LPEQ rats.

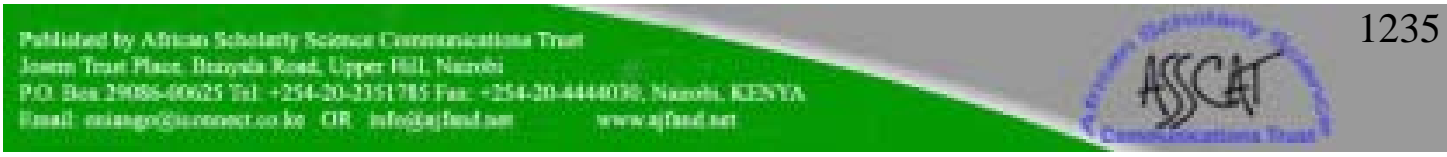




\section{CONCLUSION}

Overall, findings suggest that adequate and consistent intake of diets high in protein content may ameliorate toxic effect of concurrent intake of $\mathrm{E}$ and $\mathrm{Q}$, and inadequate protein dietary intake may enhance the toxic effects. This has clinical implications for malaria endemic developing countries where protein deficient diets, misuse/abuse of chloroquine through self-medication and alcohol use is common. Alcohol users and/or individuals undergoing $\mathrm{Q}$ treatment on a prolonged basis may need closer supervision for potential serious adverse effects. Further, protein supplementation may be advisable for these individuals to ameliorate the potential serious adverse effect of combined $\mathrm{E}$ and $\mathrm{Q}$ intake.

\section{ACKNOWLEDGEMENT}

We acknowledge with thanks the help of the Department of Anatomy, Universities of Zimbabwe and Limpopo, for the use of the laboratory facilities, and the laboratory staff for their assistance in this study. 
Table 1: Composition of experimental diets and the proximate analysis in Percentages

A: Composition of experimental diet

\begin{tabular}{|c|c|c|}
\hline Feed ingredients & Low protein diet & Normal protein diet \\
\hline Meat and bone meal & - & 5.00 \\
\hline Cotton cake & - & 10.00 \\
\hline Soya oil cake blend & - & 8.00 \\
\hline Crushed yellow maize & 23.80 & 12.00 \\
\hline Sugar & 23.00 & 15.00 \\
\hline Molasses & 5.00 & 5.00 \\
\hline Soya oil & 3.20 & 3.60 \\
\hline Limestone flour & 1.60 & 0.50 \\
\hline Monocalcium phosphate & 2.50 & 0.10 \\
\hline Salt (coarse) & 0.50 & 0.50 \\
\hline $\begin{array}{l}\text { NF P1 broiler premix } \\
\text { (FG1520) }\end{array}$ & 0.30 & 0.30 \\
\hline Maize residue & 40.00 & 40.00 \\
\hline \multicolumn{3}{|c|}{ B: Proximate analyses of experimental diets } \\
\hline Components & low protein diet & Normal protein diet \\
\hline Dry matter $\%$ & 90.49 & 89.60 \\
\hline Crude protein $\%$ & 6.19 & 14.94 \\
\hline Fat & 4.54 & 5.72 \\
\hline Crude fiber $\quad \%$ & 3.12 & 4.87 \\
\hline Ash $\quad \%$ & 6.36 & 4.99 \\
\hline Total digestible nutrients & 79.53 & 79.46 \\
\hline$(\mathrm{TDN}) \quad \%$ & & \\
\hline Gross energy (MJ/Kg) & 11.99 & 11.98 \\
\hline
\end{tabular}

Prepared and analyzed by National Foods (SAFCO), Zimbabwe. 


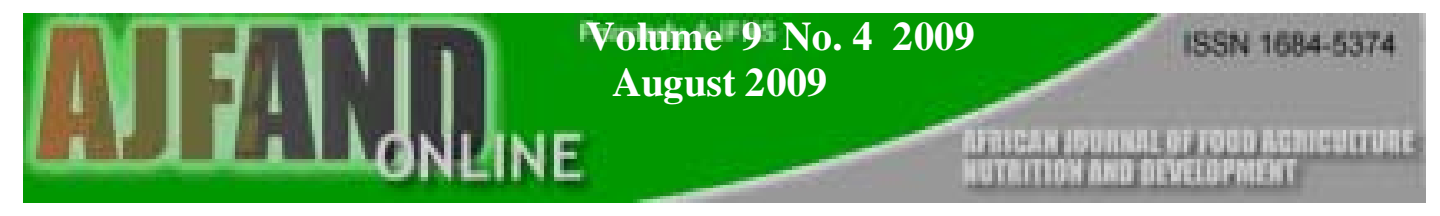

Table 2: (A and B): Percentage change in body weight and relative organ weights of rats administered chloroquine, ethanol or both and fed normal or low protein diet

\begin{tabular}{|c|c|c|c|c|c|c|c|c|}
\hline \multicolumn{9}{|l|}{ Table 2A: } \\
\hline & NPC & NPE & NPQ & NPEQ & LPC & LPE & LPQ & LPEQ \\
\hline $\begin{array}{l}\text { Body wt } \\
\text { change } \\
(\%)\end{array}$ & $17.42 \pm 1.17^{\mathrm{a}}$ & $11.03 \pm 0.30^{b c}$ & $9.01 \pm 0.23^{\mathrm{bc}}$ & $13.01 \pm 0.19^{\mathrm{bc}}$ & $9.58 \pm 1.31^{\mathrm{bc} \dagger}$ & $5.06 \pm 0.34^{\text {bc } \dagger}$ & $2.02 \pm 0.25^{\mathrm{bc} \dagger}$ & $-5.06 \pm 0.23^{\mathrm{bc \dagger}}$ \\
\hline Heart & $0.37 \pm 0.02^{\mathrm{a}}$ & $0.32 \pm 0.01^{\mathrm{b}}$ & $0.31 \pm 0.01^{\mathrm{bb}}$ & $0.31 \pm 0.01^{\mathrm{bb}}$ & $0.32^{\dagger} \pm 0.01^{\mathrm{b} \dagger}$ & $0.32 \pm 0.01^{\mathrm{b}}$ & $0.33 \pm 0.01^{\mathrm{b}}$ & $0.29 \pm 0.02^{\mathrm{bb}}$ \\
\hline Kidneys & $0.70 \pm 0.06^{\mathrm{a}}$ & $0.58 \pm 0.04^{\mathrm{b}}$ & $0.64 \pm 0.01^{\mathrm{a}}$ & $0.65 \pm 0.01^{\mathrm{a}}$ & $0.60 \pm 0.01^{\mathrm{b} \uparrow}$ & $0.62 \pm 0.01^{\mathrm{a}}$ & $0.60 \pm 0.01^{b}$ & $0.58 \pm 0.04^{\mathrm{b}}$ \\
\hline Lungs & $0.68 \pm 0.06^{\mathrm{a}}$ & $0.72 \pm 0.07^{\mathrm{a}}$ & $0.59 \pm 0.02^{\mathrm{a}}$ & $0.70 \pm 0.06^{\mathrm{a}}$ & $0.65 \pm 0.04^{\mathrm{a}}$ & $0.77 \pm 0.05^{\mathrm{a}}$ & $0.65 \pm 0.03^{\mathrm{a}}$ & $0.56 \pm 0.04^{\mathrm{a}^{\dagger}}$ \\
\hline Liver & $3.63 \pm 0.28^{\mathrm{a}}$ & $3.34 \pm 0.07^{\mathrm{a}}$ & $3.29 \pm 0.08^{\mathrm{a}}$ & $2.92 \pm 0.03^{\mathrm{b}}$ & $3.19 \pm 0.11^{\mathrm{a}}$ & $3.02 \pm 0.09^{\mathrm{bb}}$ & $3.20 \pm 0.07^{\mathrm{b}}$ & $2.96 \pm 0.25^{\mathrm{bb}}$ \\
\hline Pancreas & $0.14 \pm 0.01^{\mathrm{a}}$ & $0.13 \pm 0.01^{\mathrm{a}}$ & $0.13 \pm 0.01^{\mathrm{a}}$ & $0.15 \pm 0.01^{\mathrm{a}}$ & $0.21 \pm 0.01^{\mathrm{b} \dagger \dagger}$ & $0.17 \pm 0.01^{\mathrm{a}^{\dagger}}$ & $0.21 \pm 0.01^{\mathrm{b} \dagger \dagger}$ & $0.15 \pm 0.02^{\mathrm{a}}$ \\
\hline Spleen & $0.18 \pm 0.01^{\mathrm{a}}$ & $0.15 \pm 0.03^{b}$ & $0.18 \pm 0.004^{\mathrm{a}}$ & $0.15 \pm 0.01^{\mathrm{b}}$ & $0.14 \pm 0.004^{\mathrm{b} \dagger}$ & $0.14 \pm 0.004^{\mathrm{b}}$ & $0.14 \pm 0.003^{\mathrm{bb} \dagger}$ & $0.12 \pm 0.01^{\mathrm{bb}}$ \\
\hline Adrenals & $0.01 \pm 0.002^{\mathrm{a}}$ & $0.016 \pm 0.002^{\mathrm{bc}}$ & $0.01 \pm 0.002^{\mathrm{b}}$ & $0.01 \pm 0.001^{\mathrm{a}}$ & $0.01 \pm 0.001^{\mathrm{a}}$ & $0.02 \pm 0.003^{\mathrm{bc}}$ & $0.02 \pm 0.001^{\mathrm{bc} \dagger}$ & $0.01 \pm 0.001^{\mathrm{a}}$ \\
\hline
\end{tabular}

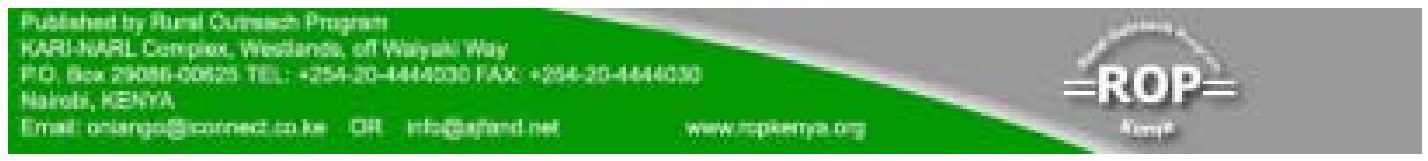




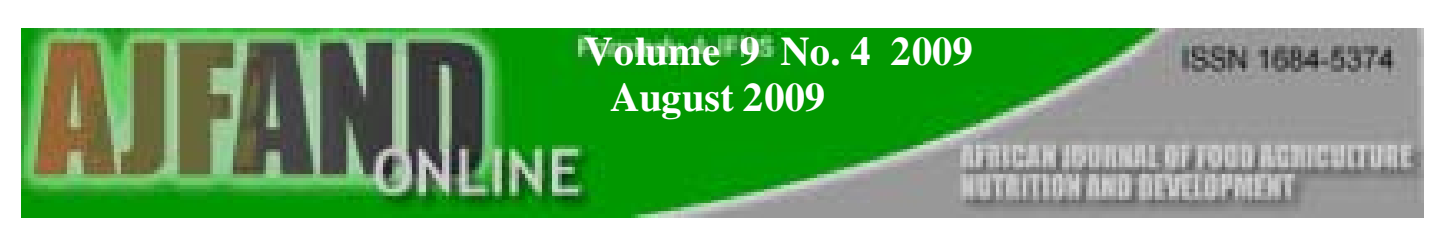

Table 2B: $p$-values for comparison of treatment groups as shown

\begin{tabular}{|c|c|c|c|c|c|c|c|c|c|}
\hline (1) & NPE/NPQ & NPE/NPEQ & NPQ/NPEQ & (2)LPC/LPE & LPC/LPQ & LPC/LPEQ & (3)LPE/LPQ & LPE/LPEQ & LPQ/LPEQ \\
\hline $\begin{array}{l}\text { Body wt } \\
\text { change } \\
(\%)\end{array}$ & 0.028 & 0.026 & 0.000 & 0.002 & 0.000 & 0.000 & 0.001 & 0.000 & 0.000 \\
\hline Heart & NS & NS & NS & NS & NS & NS & NS & NS & 0.036 \\
\hline Kidneys & NS & NS & NS & NS & NS & NS & NS & NS & NS \\
\hline Lungs & NS & NS & NS & NS & NS & 0.005 & NS & 0.003 & NS \\
\hline Liver & NS & NS & NS & NS & NS & NS & NS & NS & NS \\
\hline Pancreas & NS & NS & NS & NS & NS & 0.000 & 0.015 & NS & 0.000 \\
\hline Spleen & NS & NS & NS & NS & NS & NS & NS & NS & NS \\
\hline Adrenals & 0.042 & NS & NS & 0.001 & 0.003 & NS & NS & 0.000 & 0.000 \\
\hline
\end{tabular}

Table 2A: All values presented as means \pm SEM; ${ }^{a} \mathrm{NPC}$ and similar values; ${ }^{\mathrm{b} ; \mathrm{b} ; \mathrm{bc}}$ significantly different from NPC (b; $p<0.05 ; \mathrm{bb}$ :

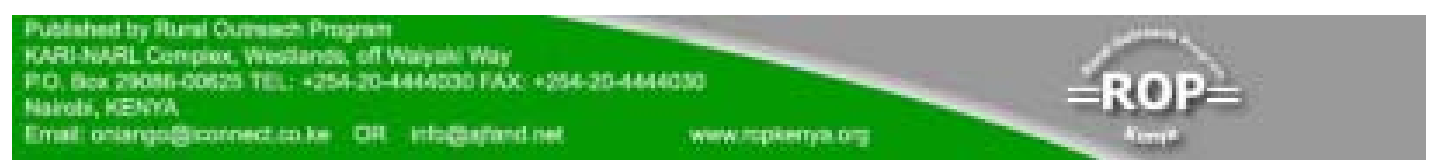




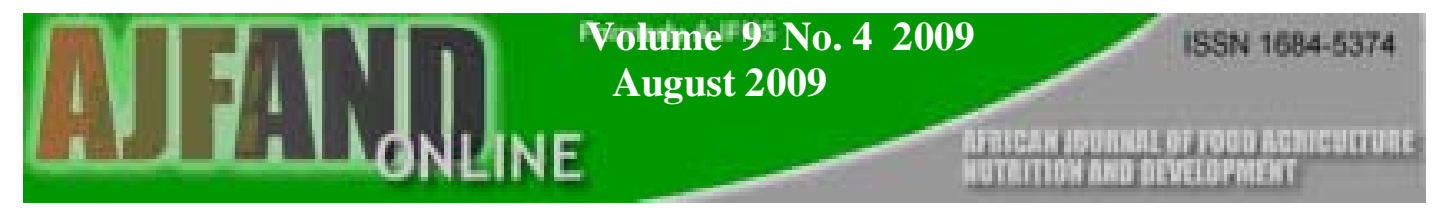

$p<0.01$; bc: $p<0.001$ ), ${ }^{\dagger}$ significant dietary effect; ${ }^{\dagger \dagger} \mathrm{p}<0.001$ ). Table 2B: Show $p$-values only; (1) and (3) show $p$-values of comparison of groups fed same diets, but placed on different treatments; (2) LPC compared to LPE-, LPQ- and LPEQ-rats.

Key: NPC; NPE; NPQ: Normal protein, control; ethanol; chloroquine, respectively. LPC; LPE; LPQ: Low Protein, control; ethanol; chloroquine, respectively. NPEQ and LPEQ: Normal and Low protein, ethanol and chloroquine combined.

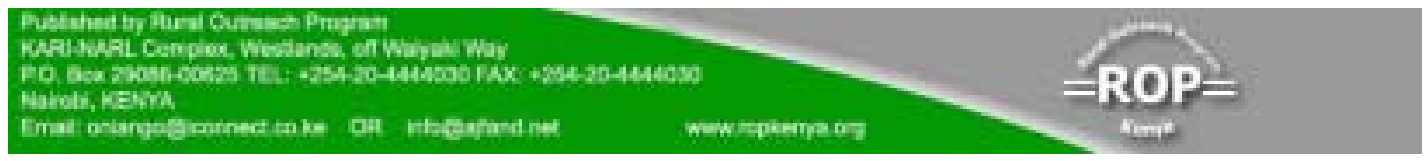




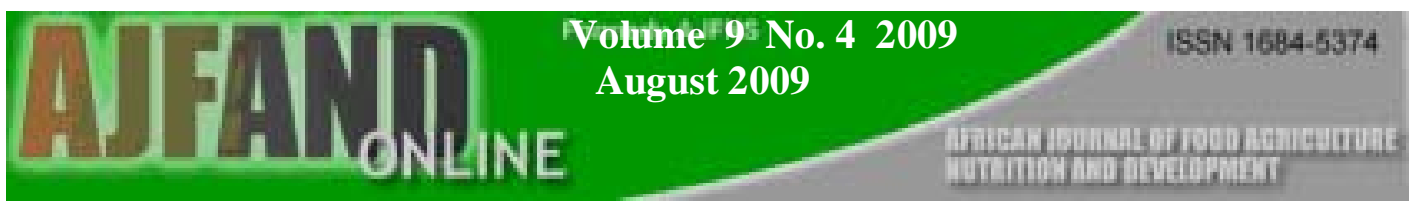

Table 3: Comparison ( $p$ - values) of some biochemical parameters of male Sprague-Dawley rat: Effects of Ethanol and/or Chloroquine in low or normal protein dietary conditions

\begin{tabular}{|c|c|c|c|c|c|c|c|c|c|}
\hline & (1)NPE/NPQ & NPE/NPEQ & NPQ/NPEQ & (2)LPC/LPE & LPC/LPQ & LPC/LPEQ & (3)LPE/LPQ & LPE/LPEQ & LPQ/LPEQ \\
\hline $\mathrm{TP}$ & NS & 0.044 & 0.002 & NS & NS & NS & NS & NS & NS \\
\hline Albumin & 0.030 & 0.014 & NS & NS & NS & NS & NS & NS & NS \\
\hline Globulin & 0.042 & NS & 0.001 & NS & NS & NS & NS & NS & NS \\
\hline $\begin{array}{l}\text { Albumin/Globulin } \\
\text { ratio }\end{array}$ & 0.018 & NS & 0.007 & NS & NS & NS & NS & NS & NS \\
\hline ALP & 0.000 & 0.004 & NS & 0.000 & 0.000 & 0.000 & 0.000 & 0.000 & 0.000 \\
\hline $\mathrm{ALT}$ & 0.000 & NS & 0.000 & 0.000 & 0.000 & 0.000 & 0.001 & 0.001 & 0.000 \\
\hline Urea & 0.002 & NS & 0.034 & 0.007 & 0.000 & NS & 0.009 & 0.031 & 0.000 \\
\hline Creatinine & 0.000 & NS & 0.000 & 0.012 & 0.000 & 0.011 & 0.000 & NS & 0.000 \\
\hline
\end{tabular}

Show $p$-values only; (1) and (3) show $p$-values of comparison of groups fed same diets respectively but placed on different treatments;

(2) LPC compared to LPE-, LPQ- and LPEQ-rats.

Key: NPC; NPE; NPQ: Normal protein, control; ethanol; chloroquine, respectively. LPC; LPE; LPQ: Low Protein, control;

Ethanol; and chloroquine, respectively.

NPEQ and LPEQ: Normal and Low protein, ethanol and chloroquine combined.

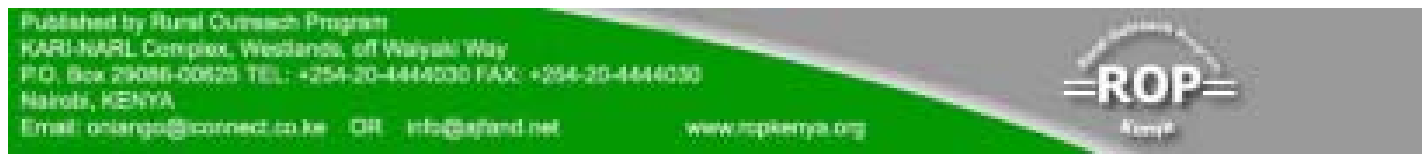




\section{REFERENCES}

1. Magwere T, Naik YS and JA Hasler Effects of chloroquine treatment on antioxidant enzymes in rat liver and kidney. Free radical Biol. Med. 1997; 22: $321-327$.

2. Adome RO, Whyte SR, Ortenblad L, Nsabagasani $X$ and AK Turinde The impact of community-based teaching on drugs: an experience from western Uganda: International conferences on improving use of medicines; WHO, Essential Medicines and Policy Department. http://mednet3.who.int/icium/icium1997/posters/3B1_TXTF.html.

3. Hayase T, Yamamoto Y, Yamamoto K, Muso E and K Shiota Stressor-like effects of cocaine on heat shock protein and stressor-activated protein kinase expression in the rat hippocampus: interaction with ethanol and anti-toxicity drugs. Legal Med. 2003; 5: S87 - S90.

4. Obatolu AV, Ketiku A and EA Adebowale Effects of feeding maize/legume mixtures on biochemical indices in rats. Ann. Nutr. Metabol. 2003; 47: 170 175.

5. Emerole GO and MI Thabrew Changes in some rat hepatic microsomal components induced by prolonged administration of chloroquine. Biochem. Pharmacol. 1983; 32: 3005 - 3009.

6. Dass EE and KK Shah Paracetamol and conventional antimalarial drugs induced hepatotoxicity and its protection by methionine in rats. Ind. J. Exptal. Biol. 2000; 38: 1138 - 1142 .

7. Santucci L, Graham TJ and DH Thiel van Inhibition of testosterone production by rat Leydig cell with ethanol and acetaldehyde: prevention of methyl-pyrazole. Alcoholism: Clin. Exptal. Res. 1983; 7: 135 - 139.

8. Musabayane CT, Cooper RG, Osim EE and RJ Balment Renal electrolyte and fluid handling in the rat following chloroquine and/or ethanol administration. General Pharmacol. 2000; 34: 43 - 51.

9. Von Schmiedeberg S, Ronnau AC, Schuppe HC, Specker C, Ruzicka T and P Lehmann Combination of antimalarial drugs mepacrine and chloroquine in therapy refractory cutaneous lupus erythematosus. Hautarzt. 2000; 51: 82 - 5.

10. Tso-Hsiao C, Po-Chiao C, Mon-Chiu C, Yuan-Fong L and L Horng-Mo Chloroquine induces the expression of inducible nitric oxide synthase in C6 glioma cells. Pharmocol. Res. 2005; 51: 329 - 336.

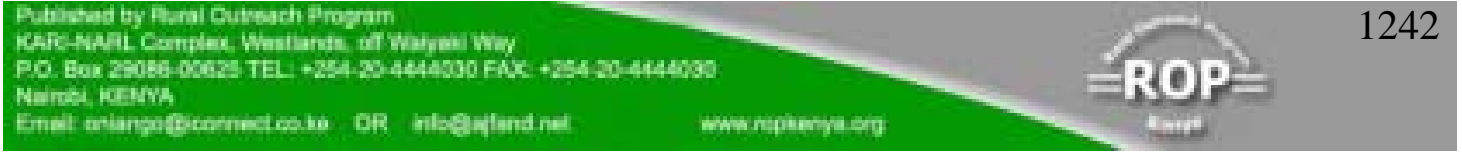


11. Akingbemi BT and TA Aire Haematological and serum biochemical changes in the rat due to protein malnutrition and gossypol - ethanol interactions. $J$. Comp. Path. 1994; 111: 413 - 426

12. Hatchcock JN Metabolic mechanisms of drug-nutrient interactions. Fed. Amer. Soc. Exptal. Biol. Proceedings. 1985; 44: 124 - 129.

13. Mbajiorgu EF, Aire TA, Vlok W, Alberts $M$ and LK Debusho Haematological profile of male rats treated with ethanol and/or chloroquine and fed normal or low protein diet. Internet. J. Haematol. 2007; 1: 1-20.

14. Nwoha PU The blood constituents of gossypol-treated, protein -malnourished Wister rats. Contraception. 1995; 52: 249 - 254.

15. ALTINfilk M, Balkaya $\mathbf{M}$, Kargin $\mathbf{F}$, Celler $\mathbf{H}$ and $\mathbf{C}$ Unsal Effects of alcohol, passive smoking and alcohol plus passive smoking on some serum biochemical variable in mice. Turk. J. Vet. Anim. Sci. 2002; 26: 369 - 377.

16. Achudume AC, Adepoju AY, Abu KA and IG Olanrewaju Experimental analysis of gossypol and chloroquine interaction in serum and in liver of rat. Ind. J. Exptal. Biol. 1998; 36: 1020 - 1022.

17. Obi FO, Maduka HCC and YP Mamza Effects of chloroquine on blood glucose and cholesterol levels in alloxan-induced diabetic rabbits. J. Biol. Sci. 2003; 3: 875 - 881 .

18. Park SH, Heo JS and CW Kang Dose-dependant effect of alcohol on insulinlike growth factor systems in male rats. Clin. Exptal. Pharm. Physio. 2004; 31: $22-28$.

19. Pari L and DR Amali Protective role of tetrahydrocurcumin (THC) an active principle of turmeric on chloroquine induced hepatotoxicity in rats. J. Pharm. Pharmaceut. Sci. 2005; 8: 115-123.

20. Duncan JR and KW Prasse Veterinary Laboratory Medicine, Clinical Pathology, $2^{\text {nd }}$ edition, Iowa State University Press, Ames, Iowa. 1987; pp 122 126.

21. Al Banchaabouchi M, Marescau B, D'Hooge R and PP De Deyn The effects of high protein diet on urea and guanidine compound levels in renal insufficient mice. Amino Acids. 2001; 4: 401 - 415.

22. Cecchin E and S De Marchi Alcohol misuse and renal damage. Addiction Biol. 1996; 1: 7 - 17.

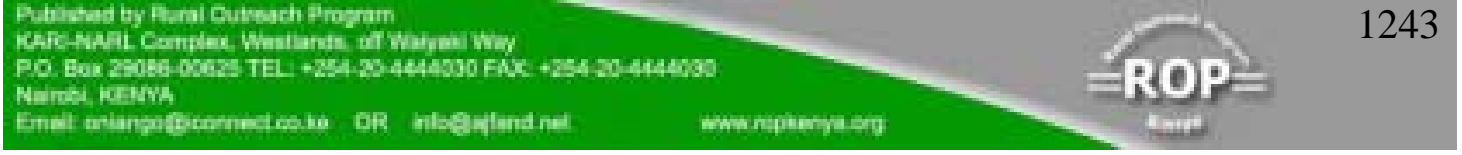


23. Murugavel IP and L Pari Attenuation of chloroquine-induced renal damage by a-lypoic acid: Possible antioxidant mechanism. Renal Failure. 2004; 26: 517 524.

24. Fatjo F, Fernandez-Sola J, Lluis M, Elena M, Babia E, Sacanella E, Estruch R and N Josep-Maria Alcohol effects on the fetus, brain, liver and other organ systems. Alcoholism: Clin. Exptal. Res. 2005; 25: $864-870$.

25. Shaw S, Jayatilleke E and CS Lieber: Lipid peroxidation as a mechanism of alcoholic liver injury: role of iron metabolism and microsomal induction. Alcohol. 1988; 5: 135 - 140.

26. Petersen DR Alcohol, iron-associated oxidative stress, and cancer. Alcohol. 2005; 35: 243 - 249. 